\title{
Studies of anthropometric indicators and their relationship with metabolic variables
}

\author{
Antonia Dalla Pria Bankoff ${ }^{12^{*}}$, Leandro Calixto Zago ${ }^{1}$ \\ ${ }^{1}$ Physical Education Faculty, Laboratory of Electromyography and Biomechanics of Posture, State University of Campinas (Unicamp), \\ Campinas, Brazil; *'Corresponding Author: dallabankoff@bol.com.br \\ ${ }^{2}$ Federal University of Mato Grosso do Sul, Campus of Três Lagoas, Brazil
}

Received 7 November 2013; revised 11 January 2014; accepted 29 January 2014

Copyright (c) 2014 Antonia Dalla Pria Bankoff, Leandro Calixto Zago. This is an open access article distributed under the Creative Commons Attribution License, which permits unrestricted use, distribution, and reproduction in any medium, provided the original work is properly cited. In accordance of the Creative Commons Attribution License all Copyrights (C) 2014 are reserved for SCIRP and the owner of the intellectual property Antonia Dalla Pria Bankoff, Leandro Calixto Zago. All Copyright (C) 2014 are guarded by law and by SCIRP as a guardian.

\section{ABSTRACT}

The purpose of this work is to identify in the anthropometrical indicators used here in this study the percentage of body fat, the body mass index (BMI) and the waist-hip ratio (WHR), which present a correlation with the metabolic variables of heart rate, blood pressure (systolic and diastolic) and double product. A population of 69 subjects averaging $41.7 \pm 6.6$ years old had their data registered by applying the Bruce Protocol modified to calculate metabolic variables; to obtain the percentage of fat, the formula of Petroski was used. The data collected received statistical treatment by the "Statistical 5.0" program with correlation being made by the calculation of the simple coefficient of Pearson " $r$ " by means of a statistical significance test $(p<0.05)$. In the results, heart rate appeared to be correlated essentially with the intensity of force, associating itself with the percentage of fat and the BMI. Blood pressure presented a good correlation with the BMI, principally in the female group. In the male group, the anthropometrical indicator that had major associations with blood pressure was the WHR, showing an association between the pattern of male body fat distribution (android) and blood pressure. The double-product had a major correlation with the BMI; however, this variable really reflects the work of the myocardium since the BMI is the only indicator used here that includes lean mass in its values. The time spent on the treadmill was correlated in a negative way only with the percentage of fat; in other words, the greater the percentage, the lesser time spent on the treadmill.

\section{KEYWORDS}

\section{Anthropometry; Body Fat; Heart Rate; Blood Pressure}

\section{INTRODUCTION}

The number of depolarizations of the sinoatrial node (SA) normally represents heart rate during the period of one minute. The heart rate is one of the cardiovascular parameters most affected by exercise, and due to being easy to measure, it is very frequently studied [1]. At the beginning of exercise, or even a little before, cardiovascular activity is activated by the neural centers above the bulbar region. Regional blood flux is altered in direct proportion to the intensity of the exercise due to adjustments that cause a significant increase of frequency and pumping force of the heart [2,3].

The power that moves blood through the circulatory system is pressure that makes blood flow from a highpressure area to a low-pressure one. This pressure fluctuates in the arteries, and for this reason, the greatest pressure obtained is called "systolic pressure" and the lowest "diastolic pressure". Effects observed during exercise, like increased cardiac debt resulting from increases in ejection volume and in cardiac beats generated by nerve and hormone influences, end up raising blood pressure. The diastolic pressure is less altered than systolic pressure by the greater amount of blood drained by the arteries through the arterioles and to the interior of the muscular capillaries. High blood pressure, systolic as well as diastolic, is referred to hypertension. This high arterial pressure is associated with numerous circulatory 
diseases [4]. Pressure is exerted by blood in the entire vascular system, being greater in the arteries where it can be measured for use as a health indicator [5-7].

The oxygen $\left(\mathrm{O}_{2}\right)$ supply should meet the demands of the myocardium so that its functioning is not threatened. Availability of $\mathrm{O}_{2}$ during exercise ought to be optimum for answering the demands caused by activity. The Double Product is obtained by the multiplication of the Heart Rate $\times$ Systolic Arterial Pressure, and it presents a significant correlation with the consumption of oxygen by the myocardium, thus:

HR $\times$ SBP $=$ Double Product [8]

There is a close relationship between excessive body fat and non-transmissible chronic diseases, like high blood pressure, coronary diseases, diabetes, lipidoses, some types of cancer and osteoarthrites that represent in the country almost half of the deaths [9]. Development of negative complications associated to excessive body fat is directly related to the amount of total fat $[5,10]$ as well as to the distribution of this fat throughout the body [2, 11].

Among the most commonly used methods for anthropometrical measurement, there are calibration of the thickness of cutaneous folds (TCF) that estimates the total amount of body fat; the body mass corporal (BMI) that considers total body weight $(\mathrm{Kg})$ of individuals relative to their height (m) $[12,13]$; and the waist/hips ratio (WHR) that has the purpose of estimating the amount of subcutaneous and internal fat by means of the relation between the circumferences at the umbilical and hip level [2]. These methodologies are a simple way to determine anthropometrical values, cost little and facilitate application [14].

Stored fat above the average pattern values is characteristic of an obese situation. Obesity can be a primary risk factor for coronary pathology as well as exercise its influence through other risk factors like high blood pressure, diabetes, less plasmatic concentration of high-density cholesterol (HDL) and hypercholesterolemia. There is a clear relation between hypertension and obesity in a casual way: it imposes a considerable risk for cerebral vascular accidents and the development of a situation of congestive cardiac insufficiency [12]. The authors relate that in Americans between 20 and 44 years old with excess weight, there was a risk observed 5.6 times higher for developing hypertension and 3.8 times more for diabetes in relation to those of the same age with normal weight.

Another anthropometrical indicator utilized frequently by practitioners and researchers is the body mass corporal (BMI) because it relates body weight (mass) with height, and evaluates "normality" of the individual's body weight. The BMI is important because of its line curve relation with mortality from all causes; with a greater
BMI, the risk of cardiovascular complications (including high blood pressure), diabetes and renal disease increases [2].

BMI = Body weight $(\mathrm{Kg}) / \operatorname{Height}^{2}(\mathrm{~m})$

In 1947, there arose the hypothesis of the importance of the distribution of body fat in clinical evaluation of obese patients that was confirmed in subsequent epidemiological studies. Android obesity (male pattern or central obesity), characterized by predominantly abdominal fat accumulation, is found principally among fat patients with hypertension, type 2 diabetes and coronary pathology. Offering less significant risk to health, gynoid obesity (female pattern or peripheral obesity) is characterized by greater deposits of excess fat in the gluteal and femoral regions [2].

This work intends to relate the behavior of metabolic variables of heart rate (HR), systolic blood pressure (SBP), diastolic blood pressure (DBP) and double product both in situations of rest and exertion (stages 1 and 2) using anthropometrical indicators as signs of health.

\section{MATERIAL AND METHOD}

The population studied in this work consists of adults between 28 and 57 years old with the average age of the whole group being $41.7 \pm 6.6$ years old (men $=42.2 \pm 6$ with a variation between 29 and 51 years old and women $=41.3 \pm 7.3$, varying between 28 and 57 years old). This group is composed of workers of the State University of Campinas of both sexes, being $n=69$ total $(n=33$ men and $\mathrm{n}=36$ women).

We used the Ergometry-TEB System, which is formed by an Ergometer APEX 2200 Treadmill, two monitors, configured for 06 protocols, and others that meet the limits of speed and tilt of the system. The system is prepared to act in automatic, semi-automatic or emergency stop. It is a system made up of 13 simultaneous channels and allows the performance of exercise tests with the classic configuration of the three leads MV5, D2M and V2M, which is the configuration used. This System starts with the speed of $1.5 \mathrm{mph}$ containing 07 stages.

For collecting data, the modified Bruce protocol was used. Its characteristics permitted a model in which we employ progressive loads by varying velocity and inclination in 3-minute stages. Since this deals with a method of great increment of work (approximately three METs) per stage, it must be applied with caution in cardiac or sedentary patients in bad physical condition. Because it was applied to a population of workers in various areas of UNICAMP, all of whom were adults, it was adjusted to these people so that the risk was kept at a minimum in the light of lack of information about their physical condition in Table 1.

Source: [15].

A pre-exertion stage was also made to improve adap- 
Table 1. Description of the modified Bruce protocol, presenting characteristics of all its stages.

\begin{tabular}{cccc}
\hline Stages & Mph & \% of inclination & Minutes \\
\hline $\mathbf{1}$ & 1.7 & $0 \%$ & 3 \\
$\mathbf{2}$ & 1.7 & $10 \%$ & 3 \\
$\mathbf{3}$ & 2.5 & $12 \%$ & 3 \\
$\mathbf{4}$ & 3.4 & $14 \%$ & 3 \\
$\mathbf{5}$ & 4.2 & $16 \%$ & 3 \\
$\mathbf{6}$ & 5.0 & $18 \%$ & 3 \\
$\mathbf{7}$ & 5.5 & $20 \%$ & 3 \\
\hline
\end{tabular}

tation to activity; after the test, four stages of recuperation were made, accompanied by monitoring heartbeats and arterial pressure. Values at rest were calibrated after the subject sat for 5 (five) minutes. To ascertain the percentage of fat, the Formula of Petroski was used because it is considered more adequate for the population in question. Values of corporal density were obtained, and then the Formula of Siri transformed these values into percentages.

To calibrate arterial pressure, a Certified sphygmomanometer and a Fleischer Duoo-Sonic stethoscope was utilized. For heart rate, a Polar Vantage N frequency meter was used.

The "Statistical 5.0" program processed information statistically. The Pearson "r" simple correlation calculation was used to verify anthropometrical indicators (independent variables) that were associated with metabolic variables (dependent variables). The relation between these variables was analyzed by means of a statistical significance test $(\mathrm{p}<0.05)$.

\section{RESULTS}

Analysis of results was based on the anthropometrical indicators of thickness of cutaneous folds (TCF), body mass corporal (BMI) and the waist-hips ratio (WHR) that in this case are independent variables because they do not suffer significant alterations during the application of the tests. These anthropometrical indicators were correlated by the Pearson coefficient with the metabolic va- riables of heart beats, systolic, diastolic and double product arterial pressure that in this situation are dependent variables because they suffer the influence of other factors and are significantly altered while applying the test. Values that presented correlation are accompanied with an asterisk “*” in (Table 2).

Thickness of the Cutaneous Folds (TCF)

As it could be expected, the heart rate had its correlation increased during the application of the test more in function of the increased demand for force than by presenting a correlation with TCF since this correlation did not occur at rest. Arterial pressure presented the correlation in practically all situations, indicating a tendency to have its levels related to TCF. For the same intensity of force, greater hear rate indicates less cardio-respiratory aptitude [16]. Due to this behavior of arterial pressure in the case of the systolic, the double product always presented the correlation with TCF, even when the heart rate did not present it as being at rest.

Body Mass Index (BMI)

[11] verified in their studies that information related to body mass index (BMI) were those that produced greater associated with systolic and diastolic arterial pressure with similar statistical values in both sexes, which reveals a substantial impact of being overweight on arterial pressure levels (Table 3 ).

Waist-Hips Ratio (WHR)

The magnitude of the relation between greater accumulation of fat in the central region of the body, and levels of arterial pressure can suffer variations in function of the amount of body fat and the impact of practicing physical activity according [11].

One metabolic variable that frequently presented correlation with the waist-hips ratio were arterial pressure for the whole and the male group with the exception of the male group at rest. The female group did not present correlation in any situation, suggesting that WHR is an anthropometrical indicator with a much greater relation with the male arterial pressure. WHR did not correlate with the time spent on the treadmill (Table 4).

\section{FINAL CONSIDERATIONS}

The inexistence of correlation of WHR with heart rate

Table 2. Pearson coefficient (r) correlating TCF with the metabolic variables of heart rate, and systolic, diastolic arterial pressure and double product at rest in stages 1 and 2 .

\begin{tabular}{ccccccccccccc}
\hline Met. Var. Group & RR R & RR 1 & RR 2 & SBP R & SBP 1 & SBP 2 & DBP R & DBP 1 & DBP 2 & DP R & DP 1 & DP 2 \\
\hline Male & 0.29 & $0.48^{*}$ & $0.55^{*}$ & $0.50^{*}$ & $0.36^{*}$ & $0.42^{*}$ & $0.47^{*}$ & $0.51^{*}$ & $0.45^{*}$ & $0.41^{*}$ & $0.44^{*}$ & $0.50^{*}$ \\
Female & -0.17 & 0.27 & $0.37^{*}$ & $0.58^{*}$ & $0.71^{*}$ & $0.73^{*}$ & $0.65^{*}$ & $0.67^{*}$ & $0.59^{*}$ & $0.34^{*}$ & $0.64^{*}$ & $0.73^{*}$ \\
Total & 0.11 & $0.37^{*}$ & $0.47^{*}$ & $0.28^{*}$ & 0.16 & $0.28^{*}$ & $0.29^{*}$ & $0.24^{*}$ & 0.22 & $0.24^{*}$ & $0.30^{*}$ & $0.41^{*}$ \\
\hline
\end{tabular}

Meanings of acronyms-RR R-Resting heart rate and stages 1 and 2, SBP-Systolic blood pressure rate and stages 1 and 2, DBP-Diastolic blood pressure rate and stages 1 and 2, DP-Double Product rate and stages 1 and 2. 
Table 3. Pearson coefficient (r) correlating BMI with the metabolic variables of heart rate, and systolic, diastolic arterial pressure and double product at rest in stages 1 and 2 .

\begin{tabular}{|c|c|c|c|c|c|c|c|c|c|c|c|c|}
\hline Met. Var Group & RR R & RR 1 & RR 2 & SBP R & SBP 1 & SBP 2 & DBP R & DBP 1 & DBP 2 & DP R & DP 1 & DP 2 \\
\hline Male & $0.42^{*}$ & $0.43^{*}$ & $0.50^{*}$ & $0.54^{*}$ & $0.39^{*}$ & $0.38^{*}$ & $0.54^{*}$ & $0.46^{*}$ & $0.37^{*}$ & $0.51^{*}$ & $0.44^{*}$ & $0.47^{*}$ \\
\hline Female & -0.15 & 0.29 & $0.39^{*}$ & $0.68^{*}$ & $0.76^{*}$ & $0.78^{*}$ & $0.74^{*}$ & $0.78^{*}$ & $0.71^{*}$ & $0.44^{*}$ & $0.68^{*}$ & $0.78^{*}$ \\
\hline Total & 0.12 & $0.34^{*}$ & $0.40^{*}$ & $0.63^{*}$ & $0.57^{*}$ & $0.60^{*}$ & $0.67^{*}$ & $0.64^{*}$ & $0.57^{*}$ & $0.49^{*}$ & $0.55^{*}$ & $0.62^{*}$ \\
\hline
\end{tabular}

Meanings of acronyms-RR R-Resting heart rate and stages 1 and 2, SBP-Systolic blood pressure rate and stages 1 and 2, DBP-Diastolic blood pressure rate and stages 1 and 2, DP-Double Product rate and stages 1 and 2.

Table 4. Pearson coefficient (r) correlating WHR with the metabolic variables of heart rate, and systolic, diastolic arterial pressure and double product at rest in stages 1 and 2 .

\begin{tabular}{ccccccccccccc}
\hline Met. Var. Group & RR R & RR 1 & RR 2 & SBP R & SBP 1 & SBP 2 & DBP R & DBP 1 & DBP 2 & DP R & DP 1 & DP 2 \\
\hline Male & 0.10 & 0.21 & 0.24 & 0.31 & $0.40^{*}$ & $0.39^{*}$ & 0.34 & $0.44^{*}$ & $0.41^{*}$ & 0.20 & 0.32 & 0.34 \\
Female & -0.17 & -0.29 & -0.14 & 0.12 & 0.16 & 0.12 & 0.08 & 0.10 & 0.12 & -0.03 & -0.04 & 0.01 \\
Total & -0.06 & -0.03 & -0.01 & $0.37^{*}$ & $0.50^{*}$ & $0.43^{*}$ & $0.36^{*}$ & $0.47^{*}$ & $0.45^{*}$ & 0.20 & $0.31^{*}$ & $0.29^{*}$ \\
\hline
\end{tabular}

Meanings of acronyms-RR R-Resting heart rate and stages 1 and 2, SBP-Systolic blood pressure rate and stages 1 and 2, DBP-Diastolic blood pressure rate and stages 1 and 2,DP-Double Product rate and stages 1 and 2.

in all cases is based on the fact that this anthropometrical indicator is related to distribution and not to the amount of corporal mass; for a heart rate, what appeared to be most influential was the amount of force necessary to mobilize this total corporal mass, independently of where it was located.

The authors [17-20] infer that individuals with a distribution pattern of android fat are associated with the presence of diabetes and possibly diseases of the cardiovascular system; in contrast, those with the gynoide type present lesser relationship with cardiovascular disease risk. In the male group, all the anthropometrical indicators presented correlation with arterial pressure in practically all moments; in the specific case of WHR, this correlation occurred at the beginning of the test, which in the case of the male distribution pattern of fat (android) shows it to be an indicator that can confirm if one population is more prone to present high levels of arterial pressure while exerting force. The levels of arterial pressure of the male group were more dependent on the greater concentration of fat in the most central region of the body than the female group [11]. In this case, WHR appeared to be an anthropometrical indicator that can be used as a parameter for guaranteeing safety to men practicing a physical activity, principally when this activity is prescribed for a group that has individuals suffering from high blood pressure.

The double-product presented higher indexes of correlation when correlating to BMI and because this anthropometrical indicator is related to the amount of corporal mass, including lean mass. This metabolic variable, since it quantifies myocardium force, makes it very useful in prescribing exercise because it can be used also as a parameter of safety when the group practicing a physical activity includes individuals with cardiovascular diseases, thus avoiding submitting that population to great risks [21].

\section{FINANCIAL SUPPORT}

Fapesp No. 96/05708-4 CNPq no. 520006/96-8.

\section{REFERENCES}

[1] Araujo, C.G.S., Bastos, M.A.P., Pinto, N.L.S. and Camara, R.S. (1980) A Frequência cardíaca máxima em nove diferentes protocolos de teste máximo. Revista Brasileira de Ciências do Esporte, 2, 20-31.

[2] Mcardle, W.D., Katch, F.L. and Katch, V.L. (2008) Fisiologia do exercício energia, nutrição e desempenho humano. Guanabara Koogan, Rio de Janeiro.

[3] Zago, L.C., Bankoff, A.D.P. and Zamai, C.A. (2007) Associação entre indicadores antropométricos e variáveis metabólicas. Revista Mineira de Educação Física, 1, 3643.

[4] Fox, E.L. and Matheus, D.K. (1983) Bases fisiológicas da educação física e dos desportos, Interamericana, Rio de Janeiro, 322-412.

[5] Powers, S.K. and Howley, E.T. (2000) Fisiologia do exercício: Teoria e aplicação ao condicionamento e desempenho. Manole, São Paulo, 252-269.

[6] Bankoff, A.D.P. and Zamai, C.A. (2011) Effects of a physical activity program on cardiac cycle events in sedentary individuals. 16th Annual Congress of the ECSS, Liverpool, 6-9 July 2011, 524-526.

[7] Bankoff, A.D.P. and Zamai, C.A. (2012) Effects of a physical activity program on cardiac cycle events in sedentary individuals. Journal of Clinical \& Experimental Car- 
diology, 3, 177-185.

http://dx.doi.org/10.4172/2155-9880.1000177

[8] Araujo, C.G.S. (1984) Manual de teste de esforço. Ao livro técnico, Rio de Janeiro.

[9] Bankoff, A.D.P. (2000) Obesidade, adolescência, atividade física e saúde. Fenômeno esportivo no início de um novo milênio. Unimep, 43-52.

[10] Lohman, T.G. (1986) Applicability of body composition techniques and constants for children and youths. Exercise and Sport Science Reviews, 14, 325-357.

[11] Guedes, D.P. and Guedes, J.E.R.P. (1997) Distribuição de gordura corporal, pressão arterial e níveis de LipídiosLipoproteínas Plasmáticas. Arquivos Brasileiros de Cariologia. http://www.scielo.br/scielo.php

[12] Pollock, M.L. and Wilmore, J.H. (1993) Exercícios na saúde e na doença: Avaliação e prescrição para prevenção e reabilitação. Medsi, Rio de Janeiro, 402-482.

[13] Leite, P.F. (2000) Aptidão física. Esporte e Saúde Robe Editorial, São Paulo, 224-284.

[14] Menezes, A.S., souza, G.S. and Duarte, M.F.S. (2003) O perímetro da cintura como preditor de sobrepeso e hipertensão arterial em mulheres idosas. Revista Brasileira de Atividade Física \& Saúde, 8, 12-18.

[15] Araujo, W.B. (1986) De ergometria \& cardiologia despor- tiva. Editora Médica e Científica Ltda, 182-245.

[16] Mcardle, W.D., Katch, F.I. and Katch, V.L. (2006) Fundamentos de fisiologia do exercício. Editora Guanabara Koogan S. A., Rio de Janeiro, 189-254.

[17] Mueller, W.H., Deutsch, M., Malina, R.M., Bailey, D.A. and Mirwald, R.L. (1986) Subcutaneous fat topography: Age changes and relationship to cardiovascular fitness in Canadians. Human Biology, 58, 435-552.

[18] Bjorntorp, P. (1997) Body fat distribution, insulin resistance, and metabolic diseases. Nutrition, 13, 795-803. http://dx.doi.org/10.1016/S0899-9007(97)00191-3

[19] Baumgartner, R.N., et al. (1986) Adipose tissue distribution: The stability of principal components by sex, ethnicity and maturation stage. Human Biology, 58, 719-735.

[20] Van Itallier, T.B. (1988) Topography of body fat: Relationship to risk of cardiovascular and other diseases. In: Lohman, T.G., Roche, A.F. and Martorell, R., Eds., Anthropometric Standardization Reference Manual, Human Kinetics, Champaign, 356-402.

[21] Bankoff, A.D.P., Zamai, C.A., Rocha, J. and Mendes Guimarães, P.R. (2013) Study on little active and sedentary women: Comparison between protocols and prospect for admission in physical activity program. Open Journal of Preventive Medicine, 3, 413-422. 